\title{
A Framework in Support of Multimodal User Interface
}

\author{
Luis Velhinho and Arminda Lopes \\ Instituto Politécnico de Castelo Branco, Escola Superior de Tecnologia, \\ Av. Do Empresário, 6000 - Castelo Branco, Portugal \\ luis.velhinho@gmail.com, aglopes@ipcb.pt
}

\begin{abstract}
Technologies (IT) Companies' Frameworks have been one of the solutions for the increasing demand for new products and services that are more and more complex and need to be delivered in the least amount of time possible. This paper presents work in progress. The goal was to evaluate Frameworks used by business enterprises and to state the advantages and disadvantages in their use. The chosen methodology for data collection and analysis was the Grounded Theory Method from which it was possible to obtain some conclusions based on given answers. With this research, the intention was is to present some recommendations for companies that work with this type of products to improve their productivity and profit.
\end{abstract}

Keywords: Company Frameworks, Content Management, Graphical User Interface, Information Technologies, Work Analysis.

\section{Introduction}

The business market has sought, in last years, to take out advantage of new technologies as a differentiation factor for better productivity and to reach new customers. This increased demand has brought pressure to the suppliers of IT to provide products and services of greater complexity on a reduced time.

The IT companies meet their expectations supported on their customers' claims, and they found solutions thinking in profit incomes. For many companies one of the ways to be different and to respond to this challenge has been the Frameworks development which allows accumulating knowledge and experience that exist within the company and to improve their products' quality.

According IBM [5] "A Framework is a set of blocks of pre-fabricated software that programmers can use to apply, or change specific computing solutions. (...) With the Frameworks the software developers do not need to start from beginning each time they start building an application. Frameworks are built from a collection of objects, so far as the design codes to be reused."

In this research we try to analyze the impact of these types of tools inside companies, and we will try to understand the following concerns:

- To understand the segment markets where the Companies Frameworks are used furthermost;

- To identify the advantages of using Frameworks for enterprise businesses as well as for the development teams; 
- $\quad$ To understand the decision factors considered for the choice of a framework and the customers' satisfaction;

- To detect key requirements in the creation of Frameworks;

- To identify areas of improvement on the Frameworks.

\section{Frameworks}

Frameworks can be classified according two dimensions [7]: where the framework is used and how it is used. And they can be regarded in three distinct ways:

- White-Box - where the developer modifies or extends existing functionality by defining or overlapping methods.

- Black-Box - where the developer uses functions already presented in the Framework (the internal modules of the Framework cannot be viewed or altered and interfaces already defined must be used).

- Hybrids - has the same behavior as the White-Box and Black-Box

Frameworks are used by companies with different goals. It depends on the type of use that the company intends to do. In some cases, they only intend to have a tool that helps in a simple project's development, but in other cases, they intend to develop a tool that has a huge amount of data and logic definitions.

\subsection{Framework Wizy}

Wizy is an agile development Framework that we use within the enterprise. It enables rapid creation of web applications based on web front ends (Fig. 1.). It was created as a platform to allow fast development of multiple application projects. Conversely, it offers an entire multi-runtime application with embedded functionality for content

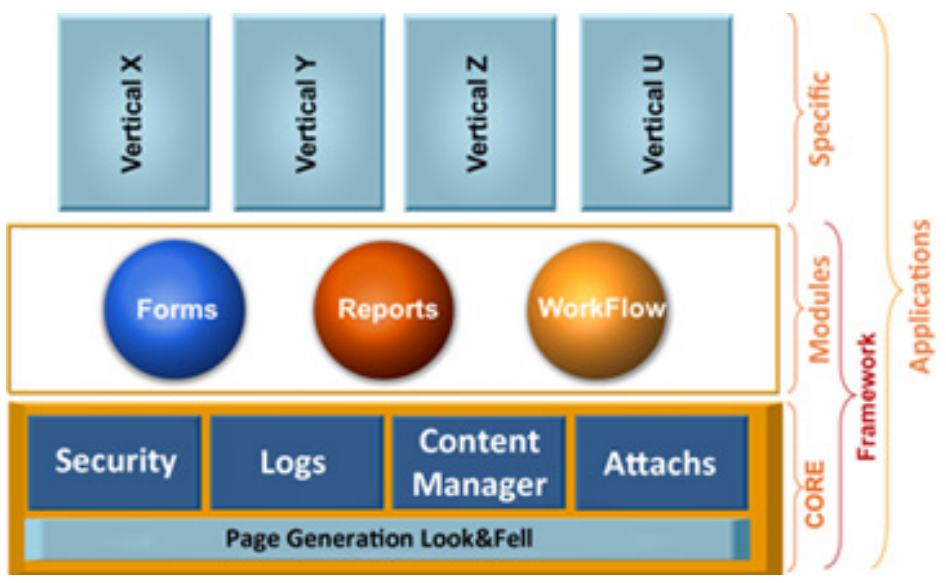

Fig. 1. Wizy Structure Organization [9] 
management and workflow. The dispersed data is aggregated in a standard manner allowing content management in a flexible way, providing libraries and components that let prompt development for custom applications.

Typically, a framework is composed for several organizational layers that allow a higher abstraction view for anyone working with the Framework [6].

Fig. 2. presents an example of the Framework Wizy structured on 4 layers. The first layer, External Systems, is the whole systems that interact with Framework. The second layer, Content Provider, provides interfaces to interact with internal and external systems. The third layer, the Content Aggregation, is where all contents are aggregated into one default or custom ASPX page. The fourth layer Content Presentation is shared between Server and Client: the server sends the page on XML and applies XSLTs and CSS styles. The client browser interprets the whole data and shows the page to the user.

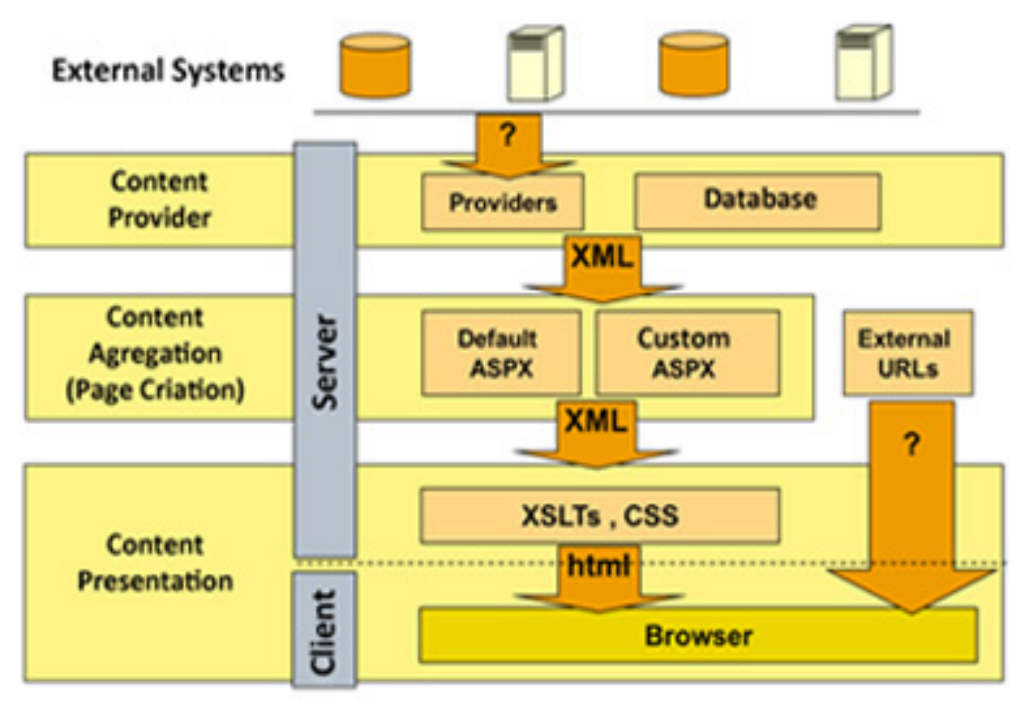

Fig. 2. Framework Wizy Layers [9]

\section{$3 \quad$ Research Methodology and Methods}

Grounded Theory Methodology was developed by Glaser \& Strauss [3]. It is a general methodology for developing theory that is based on data systematically collected and analyzed [8]. Grounded Theory (GT) is a general method to use on any kind or combination of data, and it is particularly useful with qualitative data.

The main goal of this approach consists of a set of steps which will "guarantee" a good theory as the outcome. It involves two phases in the analysis of qualitative data. Data fragments are compared in order to derive concepts and categories which catch their analytically relevant properties. The second phase is used to elaborate, refine and reduce results of the first phase. 


\subsection{Research Methods}

This research was prepared for business companies which mission is to invest in software development for clients who wants customized applications to manage and improve their business.

This study was conducted through the use of different research methods. Data was collected from staff interviews, observations, and surveys. Interviews were conducted with staff from 11 Portuguese companies whose core business was IT consultancy operating in several target markets with over 5 million euros.

Interviews were face to face, on a private room, and with the interviewees' authorization. They were audio recorded. Later, a transcript of the interview was made. Based on a script several questions were asked and the researcher took also some notes.

Finally, an anonymous online survey for IT developers was made through programming forums, social networks, e.g. LinkedIn. The forum's participants were software developers who worked with multiple Frameworks.

\section{Work Analysis Procedures}

The main motivation of this research was the researcher's concern about several rejected projects from customers at the end of an order. The intention was to try to understand and find out the reasons that led projects to this end.

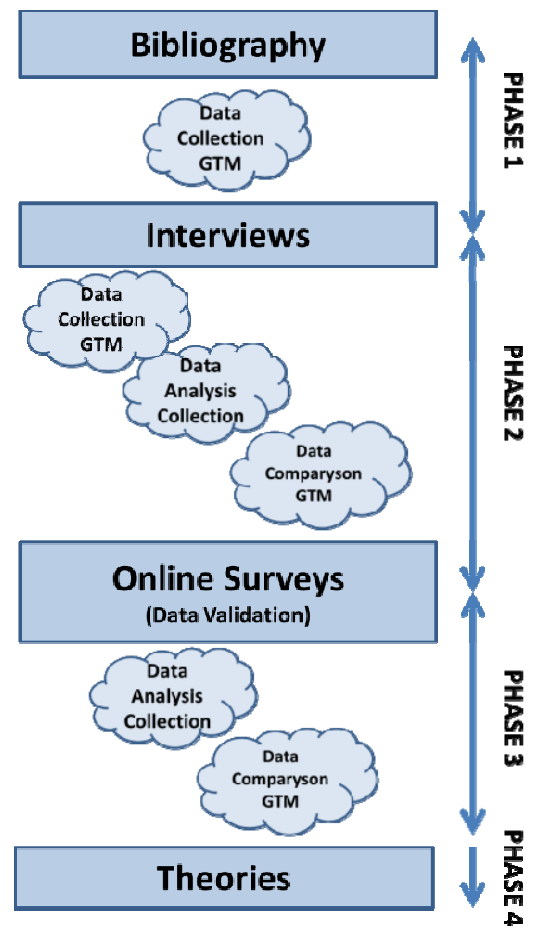

Fig. 3. Research Methodology Phases 
This research was carried out through several phases. Initially, we started reading literature, namely, Fayad [2] and technical documentation about object-oriented application frameworks. When applying GTM preconceived conceptions it should not be feared but instead serve as a starting-point for looking at data. After this initial data collection and analysis phases, we decided to make interviews. Interviews permitted to have rich data through a constant comparative method which constitutes the core of grounded theory, ideas started to be organized but needed to be validated. To validate the analyzed data and to keep the GTM process of constant comparison analysis, we decided to do an anonymous online survey. Several IT companies were invited to collaborate in completing the survey. Fig. 3. presents the several phases for data collection, analysis and comparison.

On Phase 1 we start by searching and reading bibliography to begin the data collection GTM process. On Phase 2 the interviews were conducted and respective data analysis and collection was made. Interviews demanded a preparation process before: background information about Companies' Frameworks were collected through books and internet articles which permitted to understand, as well as, to describe Frameworks' components and the way they work. The researchers only considered to interview people with around six years of experience in the companies. After this data collection phase the data was compared with the previous dataset.

Online surveys for data validation, on phase 3, were designed. Phase 3 also included the data gathered analysis and respective comparison with other phases. On Phase 4 we start defining the final theories of the process.

The work analysis process, following GTM, was, initially, based on the literature, different set of profiles were identified to establish a set of questions according to interviewees' experience (see table 1.).

Table 1. Profiles Description

\begin{tabular}{|l|l|}
\hline \multicolumn{1}{|c|}{ Profile } & \multicolumn{1}{c|}{ Description } \\
\hline Developer & $\begin{array}{c}\text { Basic element of the hierarchy that develops projects over } \\
\text { the Framework. }\end{array}$ \\
\hline Team Leader & $\begin{array}{l}\text { Coordinator element of the team development that manag- } \\
\text { es the resources in accordance with the project plan. }\end{array}$ \\
\hline Project Manager & $\begin{array}{c}\text { Project manager who controls and analyzes the various } \\
\text { stages of the project, is the bridge between the development } \\
\text { team and the client. }\end{array}$ \\
\hline Support & $\begin{array}{l}\text { Element responsible for providing application support to } \\
\text { the Framework or to the products built upon the Framework. }\end{array}$ \\
\hline Tester & $\begin{array}{l}\text { Element that performs the tests of the project according to } \\
\text { the requirements. }\end{array}$ \\
\hline Architect & $\begin{array}{l}\text { Element responsible for defining the architecture of the so- } \\
\text { lution. He is the person who defines the structure of the } \\
\text { Framework and defines the features to be implemented. }\end{array}$ \\
\hline Soft Director & $\begin{array}{l}\text { Responsible for I\&D is who controls the investment and } \\
\text { define the product roadmap. }\end{array}$ \\
\hline
\end{tabular}


After face-to-face interviews, we did memo-writing which has high priority in the process of constructing a grounded theory. Memo-writing is the pivotal step between data collection and the draft. When an idea was got, "It prompts you to analyze your data and codes early in the research process', [1].

The reading and note taking processes about frameworks led to a spreadsheet elaboration with some questions that should be asked to interviewees. It was realized that their different profiles required different kinds of questions. A developer, for example, sees the Framework on a different way that a supporter or an architect do.

Defined the profiles and questions, meetings were scheduling with all the persons. It was decided to start with some of researcher's colleagues to get more experience and to help in the questions' redefinition.

When the interviews were concluded a new phase arose, the data transcription and analysis. From that moment, different codes were defined to give rise to several categories. This analysis process was made with other spreadsheet and from there charts and diagrams were constructed. An example of data analysis for one of the answered questions by interviewees is presented on fig. 4 .

Question: What are the advantages of using Frameworks by business enterprises?

CODES

- Reduced cost of the project with people

- Makes the development of the project more faster $\rightarrow$

- Speed of implementation

- Accelerates the development

- Lower investment to have a solution

- Companies have common platform that allows faster responses to customers needs
CATEGORIES

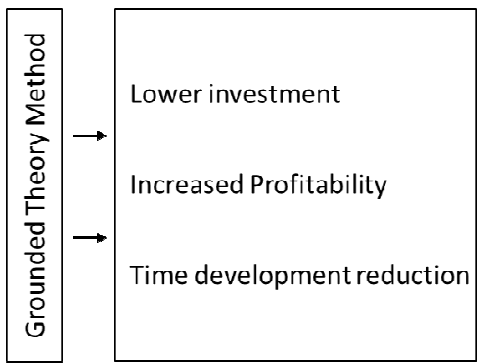

Fig. 4. Grounded Theory Method

\section{$5 \quad$ Results and Discussion}

After data analysis it was found that business sectors that most use Companies Frameworks are those of Telecommunications and Media, High Tech, Financial Services and Public Administration as shown in Fig. 5.

About $89 \%$ of respondents have worked with a Framework and from these $43 \%$ have between 6 and 10 years of experience. 


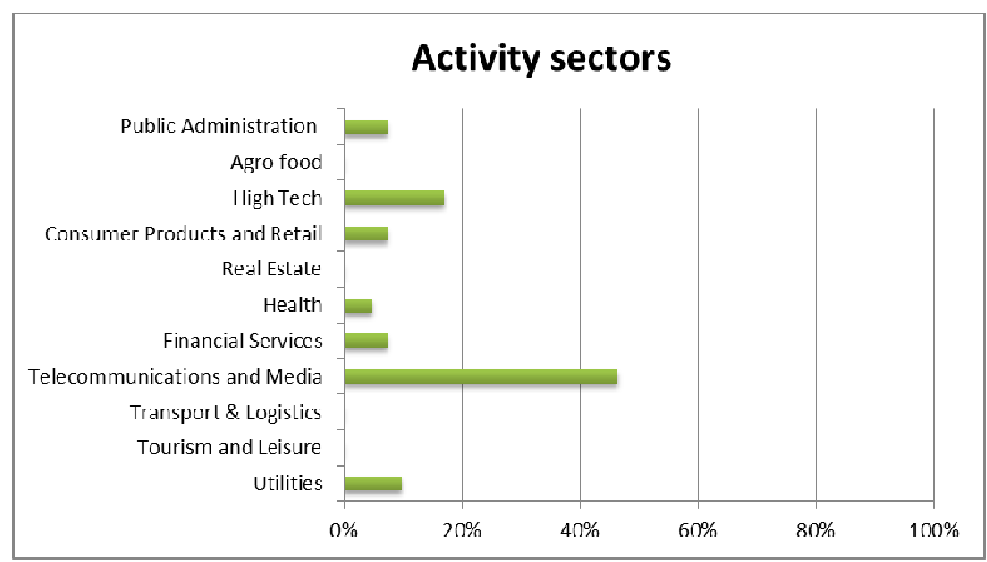

Fig. 5. Activity Sectors

Considering the main categories found within the GTM analysis we could understand that the benefits for developers who have worked with the frameworks were among others the speed of implementation, structuring, reuse and efficiency. The major identified drawbacks were the lack of documentation and the costs of introducing new features as well as versatility of the Framework in accordance with certain customer requirements.

For companies, the most obvious advantages for the use of frameworks are the increase on productivity associated with a shorter development time, the profitability improvement and the creation of standards inside the company (Fig.6.).

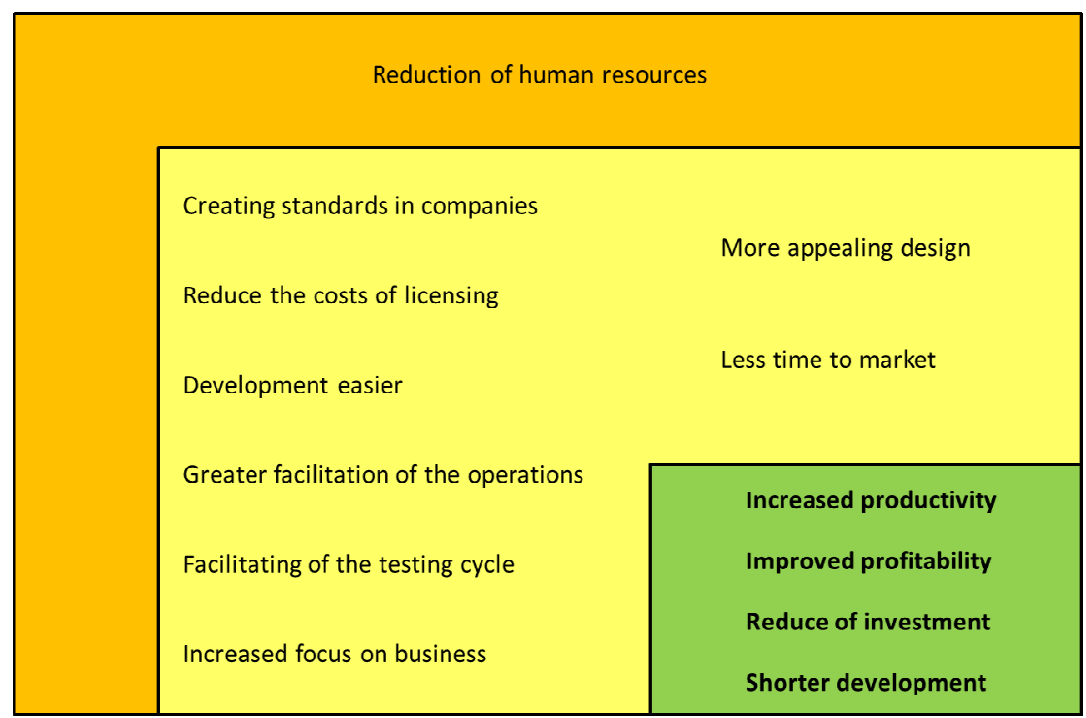

Fig. 6. Frameworks advantages 
Some keys factors considered good practices to the creation of Frameworks were also identified: formation, implementation speed, performance and security. It was interesting to see that the average investment by companies on these products is between $10 \%$ and $15 \%$ of their budget.

From the interviewees' responses it was considered that the support for multiples systems is a challenge for the future, side by side with the frameworks' versatility and adaptability, and also the continuous evolution and the introduction of new features in the framework.

The companies that are betting on this type of product, a framework, although they are achieving great profitability, they need to do some more work concerning new solutions to their customers.

\section{Conclusions}

This research was important and it permitted to have some answers to the initial questions from the interviewees and from the online survey.

The data analysis showed that there are some activity sectors that invest more in this type of products than others, for example, the Telecommunications' sector.

Many users highlighted some key attributes on the advantages of using Frameworks like: time development reduction and the increase of profitability.

Two of the major evident concerns are the lack of documentation and learning courses about the frameworks' use. On these referred areas, companies need to do some effort to improve the quality of utilization of the Framework.

In resume the Frameworks are useful for companies, they allow to reduce costs and increase productivity, besides allowing offering new and innovative products to its customers.

\section{References}

1. Charmaz, K.: Constructing Grounded Theory. A Practical Guide Through Qualitative Analysis. Sage Publications limited (2006)

2. Fayad, M., Schmidt, D.: Object-Oriented Application Frameworks (September 28, 2006), http://www.cs.wustl. edu/ schmidt/CACM-frameworks.html (retrieved March 14, 2012)

3. Glaser, B., Strauss, A.: The discovery of grounded theory. Aldine, Chicago (1967)

4. Govoni, D.: Java Aplications Frameworks. Wiley (1999)

5. IBM. Building Object-Oriented (November 26, 1997), http: / / lhcb-comp. web. cern. ch/1hcbcomp/Components/postscript/buildingoo.pdf (retrieved March 14, 2012)

6. Johnson's, R.: Frameworks Home Page (September 15, 1997), http://stwww.cs.illinois.edu/users/johnson/frameworks.html (retrieved March 14, 2012)

7. Sauvé, J.P. (n.d.): Tipos de frameworks, http://www.dsc.ufcg.edu.br/ jacques/cursos/map/html / frame/tipos.htm (retrieved March 17, 2012)

8. Strauss, A., Corbin, J.: Grounded Theory methodology: An overview. In: Denzin, N.K., Lincoln, Y.S. (eds.) Handbook of Qualitative Research. Sage Publications, London (1994)

9. Wedotechnologies, Framework Wizi Portugal (2006), http: / /www. wedotechnologies.com/pt (retrieved January 2, 2012) 